\title{
Eating Red meat and Symptomatic Lower Urinary Tract Infection among female students at King Abdul-Aziz University in Rabigh, Saudi Arabia Iman Mohmad Wahby Salem ${ }^{(1)}$, Soad Shaker Ali ${ }^{(2)}$, Fatma Ibrahim Al Bllady ${ }^{(3)}$, Ebtihal Mohammed Saleh Albeshri ${ }^{(4)}$ \\ ${ }^{(1)}$ Family and Community Medicine Department, Faculty of Medicine, Rabigh, KAU and Al-Azhar University, \\ (2) Anatomy Department, Faculty of Medicine, Rabigh, KAU, ${ }^{(3)}$ Internal Medicine Department, Faculty of Medicine, Rabigh, KAU, ${ }^{(4)}$ Undergraduate student, Faculty of Medicine, Rabigh, KAU.
}

\begin{abstract}
Background: Chronic diseases, such as diabetes, hypertension associated-heart disease; and several different cancers were reported to be linked to high meat consumption. Assessment of urinary nutria-metabolomics was also considered and reported as a novel tool for dietary styles. Increased consumption of red meat was associated with increased risk of bladder diseases and infection. Method: This is a cross-sectional study conducted among the Rabigh colleges' female students throughout 10 months, for measuring the prevalence of symptomatic lower urinary tract infection (LUTI) at King Abdul-Aziz University, Rabigh, Saudi Arabia, 2019. The questionnaire was distributed among 200 students through their mobile via WhatsApp. It was calculated by the sample size equation, using a mean prevalence of LUTI among teenage female. Result: Among the 230 students who received the questionnaire, the response rate was $66 \%$, so the total current studied sample was 152 female students from different colleges in Rabigh. $75.66 \%$ of them in age (1524 years), and $24.34 \%$ of them were in age (25-30 years), $23.68 \%$ of them were married, and $78.29 \%$ were eating red meat. UTI prevalence was $25.66 \%$. There was a high percentage (66.7\%) of UTI among the young female (15-24 years), the married women (35.9\%), the group who don't drink enough water $(69.2 \%)$, and $59.0 \%$ with a high rate of eating meat ( 2 times/ week). All these differences were found to be statistically significant $(\mathrm{P} \leq 0.05)$. Conclusion: LUTI symptoms seemed to be related to increased trend towards red meat eating besides other factors e.g. water drinking and marital status.
\end{abstract}

Keywords: Eating Red meat, Symptomatic Lower Urinary Tract Infection, female students.

\section{INTRODUCTION}

Essential amino acids and micronutrients needed for body health were well known to be obtained via consumption of red meat ${ }^{(1)}$. However, chronic diseases, such as diabetes ${ }^{(2)}$, hypertension associatedheart disease (3) and several different cancers were reported to be linked to high meat consumption ${ }^{(4,5)}$ Biomarkers for meat intake could be detected in urine ${ }^{(6,7)}$. Assessment of urinary nutrimetabolomics as a novel tool for dietary styles was also reported ${ }^{(8)}$.

Reviewing literature showed that increased consumption of red meat was associated with increased risk of bladder cancer e.g. Crippa, et al. (2018) ${ }^{(9)}$ who reported that five cohort studies done on considerable number of cases pointed to a link between increased red meat consumption and cancer bladder.

Values of urine $\mathrm{pH}$ in normal persons ranged between 4.5 and 8.0. Acidic urine with $\mathrm{pH}<6$ was known to cause bladder urothelial irritation that is evoking cystitis symptoms ${ }^{(10-12)}$. Cystitis as a symptom of UTI is characterized by bladder pain or discomfort and is clinically confused with what was known as bladder pain syndrome (BPS). Some cases with unknown understood etiology are challenging clinical problems and so difficult to be diagnosed ${ }^{(13)}$. Many factors can predispose to cystitis such as mild infections (14), chemical irritation and neurogenic over active bladder conditions ${ }^{(15)}$. Acute simple cystitis is referred to conditions involving the bladder mucosal lining with symptomatic urgency, frequency and suprapubic pain ${ }^{(13,16)}$.

Acute simple cystitis could be easily self-diagnosed and treated by appropriate increase water intake and simple antibiotic course but if neglected and untreated it may be complicated and ending in precancerous bladder changes ${ }^{(17)}$ and in some cases upper tract involvement with subsequent kidney damage ${ }^{(5)}$

Decreased quality of life in persons suffering cystitis via disrupting normal daily activities were reported in conditions associated with lower urinary tract disorders ${ }^{(18)}$ and this encouraged the design of the present study.

The main objective of this study was to carry out a across sectional study to evaluate the prevalence of symptomatic lower tract infection (dysuria, frequency, and hematuria) among teenage female students in Rabigh university collages, King Abdul-Aziz University and to define its link to their dietary style especially consuming diet rich in red meat. 


\section{Subjects and study design:}

This is a cross-sectional study conducted for measuring the prevalence of symptomatic LUTI at King Abdul-Aziz University in Rabigh, Saudi Arabia, 2019.

The study protocol was approved by the Local Ethics Committee. A total of 200 students were enrolled in online questionnaire. Students' consent was taken before starting the study.

- Study duration: 10 months during 2018- $1439 \mathrm{H}$

- Study area: colleges in Rabigh King Abdul-Aziz University.

- Participants Population: all female students in Rabigh colleges

- Inclusion criteria: all female students in Rabigh colleges who accept to charring in answering the questionnaire.

\section{The sample size:}

It was calculated by the sample size equation, the mean prevalence of lower urinary tract infection among teenage female was approximately $19 \%$ from a study, which was conducted by Farrel et al.and Nguyen and Weir ${ }^{(19,20)}$ which concluded that twenty-six percent of the women reported problems of UI. The prevalence of UI in younger women was $12 \%$, so we take the mean of this two number from the two previous studies ${ }^{(19,20)}(26+12 / 2=19)$.

The significance level of $\alpha=0.05$.

The minimum required sample was 230 to represent a population of students enrolled at colleges at King Abdul-Aziz University calculated by the equation:

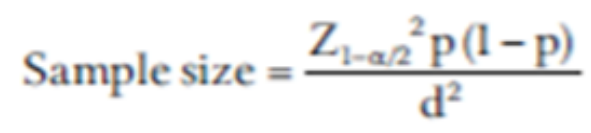

Z1- $\mathrm{a} / 2=$ Standard normal variate (at 5\% type 1error $(\mathrm{P}<0.05)$ it is 1.96 .

$\mathrm{p}=$ Expected proportion in population based on previous studies or pilot studies.

$\mathrm{d}=$ Absolute error or precision - which should be decided by researcher.

Sample size $=(3.841) * 0.19 *(0.81) /(0.0025)$

\section{Sampling procedure}

The questionnaire was distributed among 230 of the students through their mobile via WhatsApp application from one student to another compatriots (snow ball method).

\section{Research Instrument.}

A self-well-structured and reviewed Arabic questionnaire developed from questionnaires used in other previous studies was reviewed and validated by three experts in community medicine. The questionnaire was modified to be suitable for culture and the study population and submitted on google drive (https://docs.google.com/forms/d/1gUHPW7tXn2Lsuqvsvpi MmeSxe2jiG7cV2K-

N9kMo/edit?ts=5b2e6a50\#responses) to the students through the WhatsApp.

The questionnaires consisted of closed ended questions that included three sections:

- The first section asks about demographic and background information including age, name of college, marital status, and blood group.

- The second section asks about eating habits e.g. red meat eating, presence of chronic diseases as diabetes mellitus.

- The third section asks about symptoms of lower urinary tract involvement (dysuria, frequency, and hematuria), visiting clinics or hospitalization and history of taking any management (diagnosis and antibiotic treatment).

\section{Data entry and data Analysis:}

The data were coded and entered to SPSS software version 23. The data were described and cleaned before analysis. The descriptive data were analyzed according to the type of variables: The quantitative data were described by means and standard deviation (SD). Qualitative variables were described by numbers and proportions and were compared by Chi Square test. Regression models was used for multivariable analysis.

\section{RESULTS}

There were 230 students who received the questionnaire as a google drive link and the response rate was $66 \%$, so the total current studied sample was 152 female students from different colleges in Rabigh. 

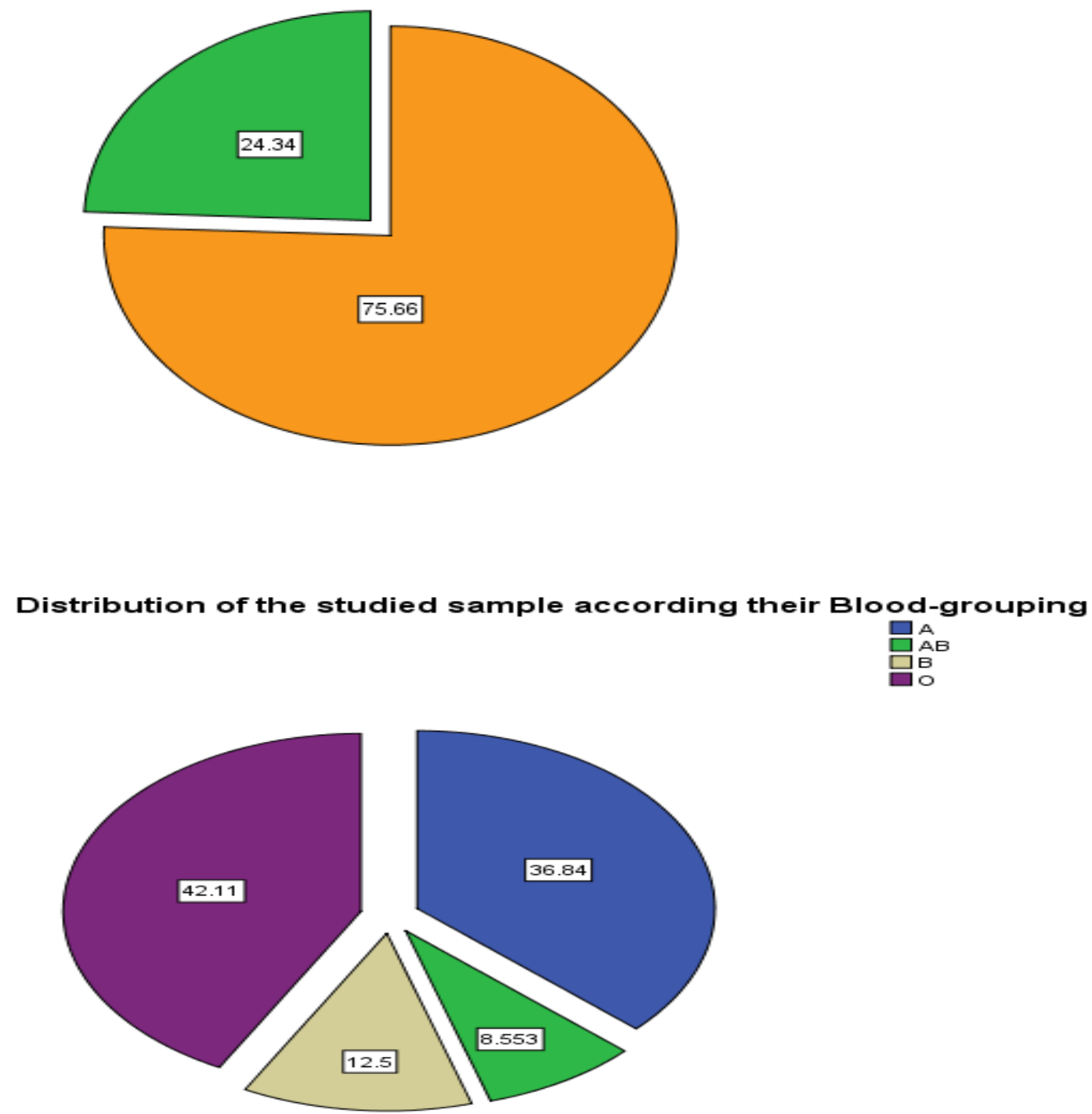

Figure (1) showed the age distribution of the studied sample. (There is no need to repeat the data in the figures and tables)

Figure (2) illustrates the distribution of the studied sample according to their blood group. 
Distribution of the studied sample according to marital status

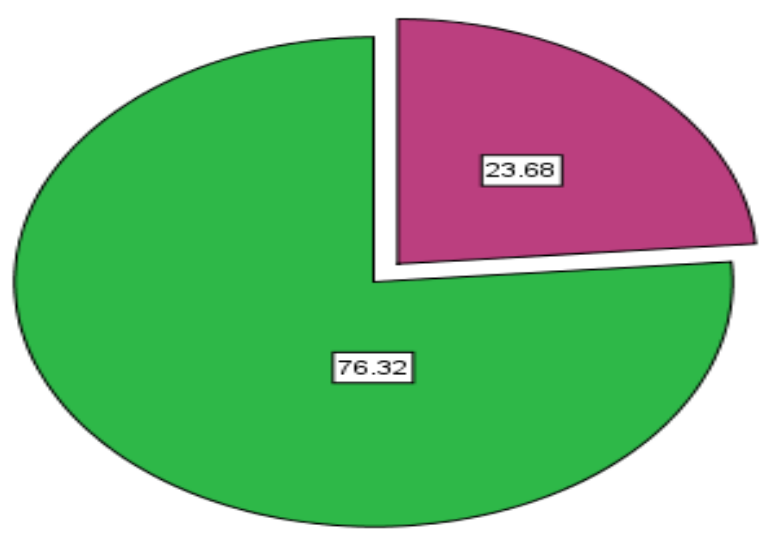

\section{Diabetes distribution among the studied sample}

$\square$ Yes

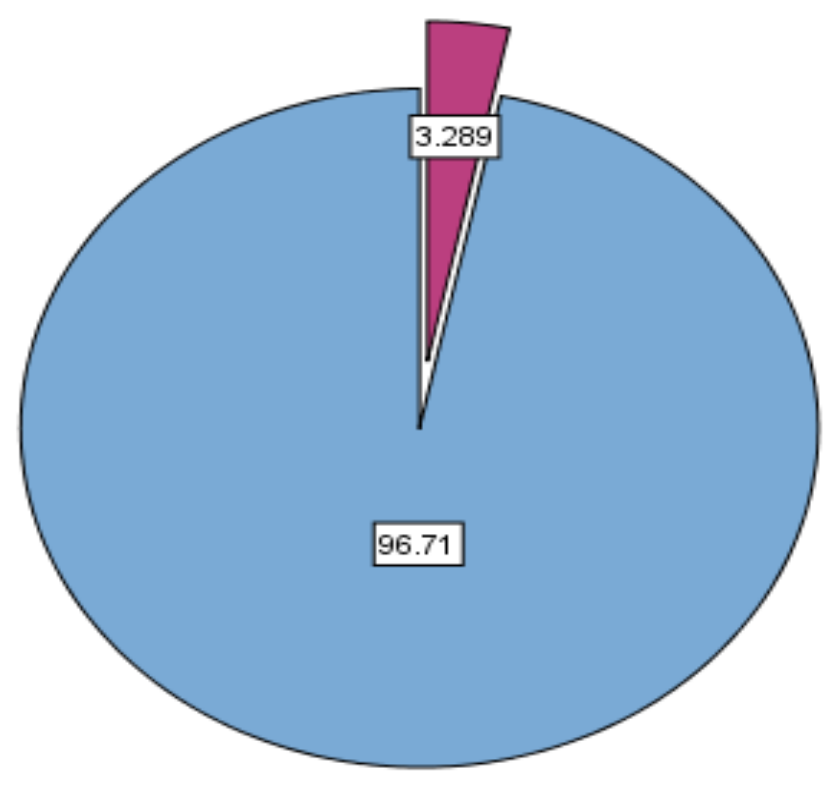

Figure (3) shows the marital status of all the female students.

Figure 4 shows diabetes distribution among all the studied sample. 


\section{Percentage of UTI among the studied sample}

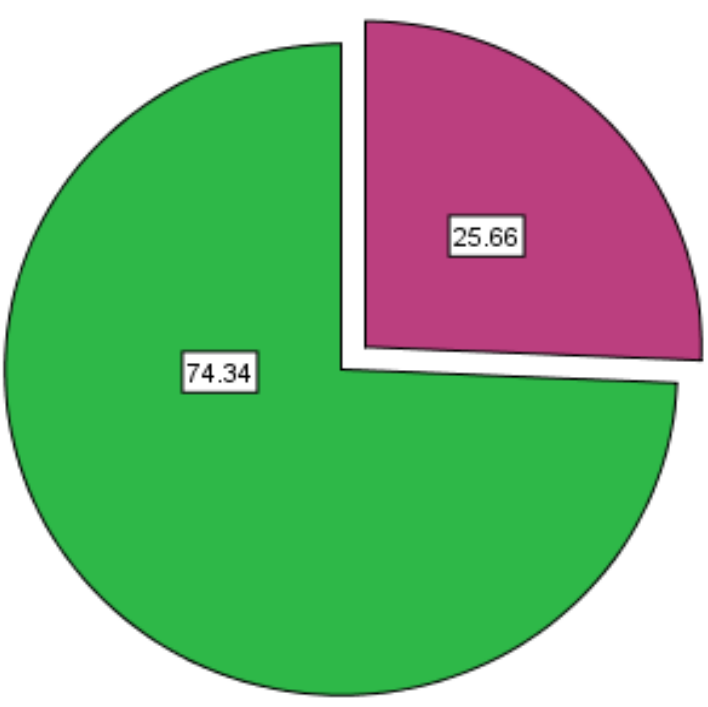

Percentage of Eat Meat among the studied sample $\square$ Yes

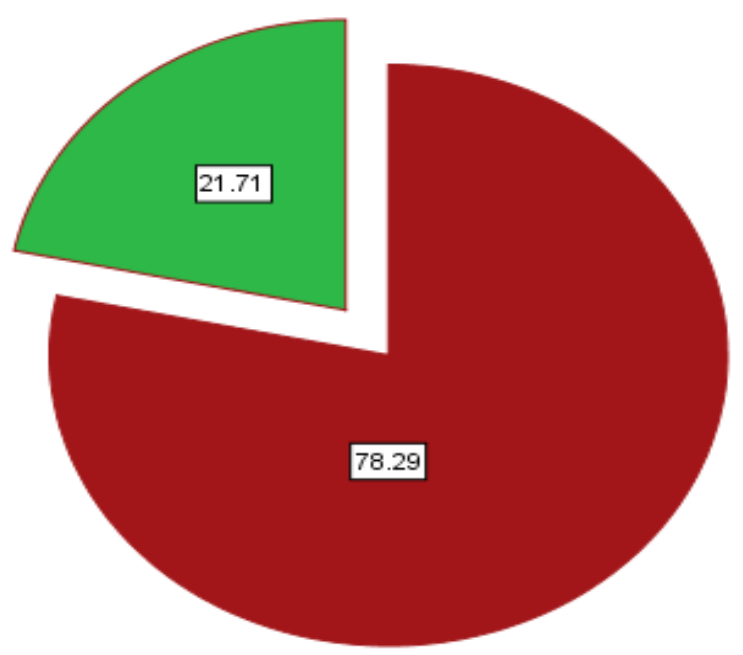

Figure (5) shows the prevalence of UTI among the studied sample which was $25.66 \%$.

Figure (6) reveals the prevalence of eating meat among the studied sample which was $78.29 \%$. 
Table (1) weight and height of the studied sample

\begin{tabular}{|l|c|c|}
\hline & Mean \pm SD & Range \\
\hline Weight (Kg.) & $59.78 \pm 12.914$ & 57 \\
\hline Height $(\mathbf{C m})$ & $156.73 \pm 7.119$ & 71 \\
\hline
\end{tabular}

Table (1) shows the mean weight in $\mathrm{Kg}$. and height in $\mathrm{cm}$. of female students.

Bivariate analysis:

Table (2) differentiation of the sample characteristic according to UTI affection among the studied sample.

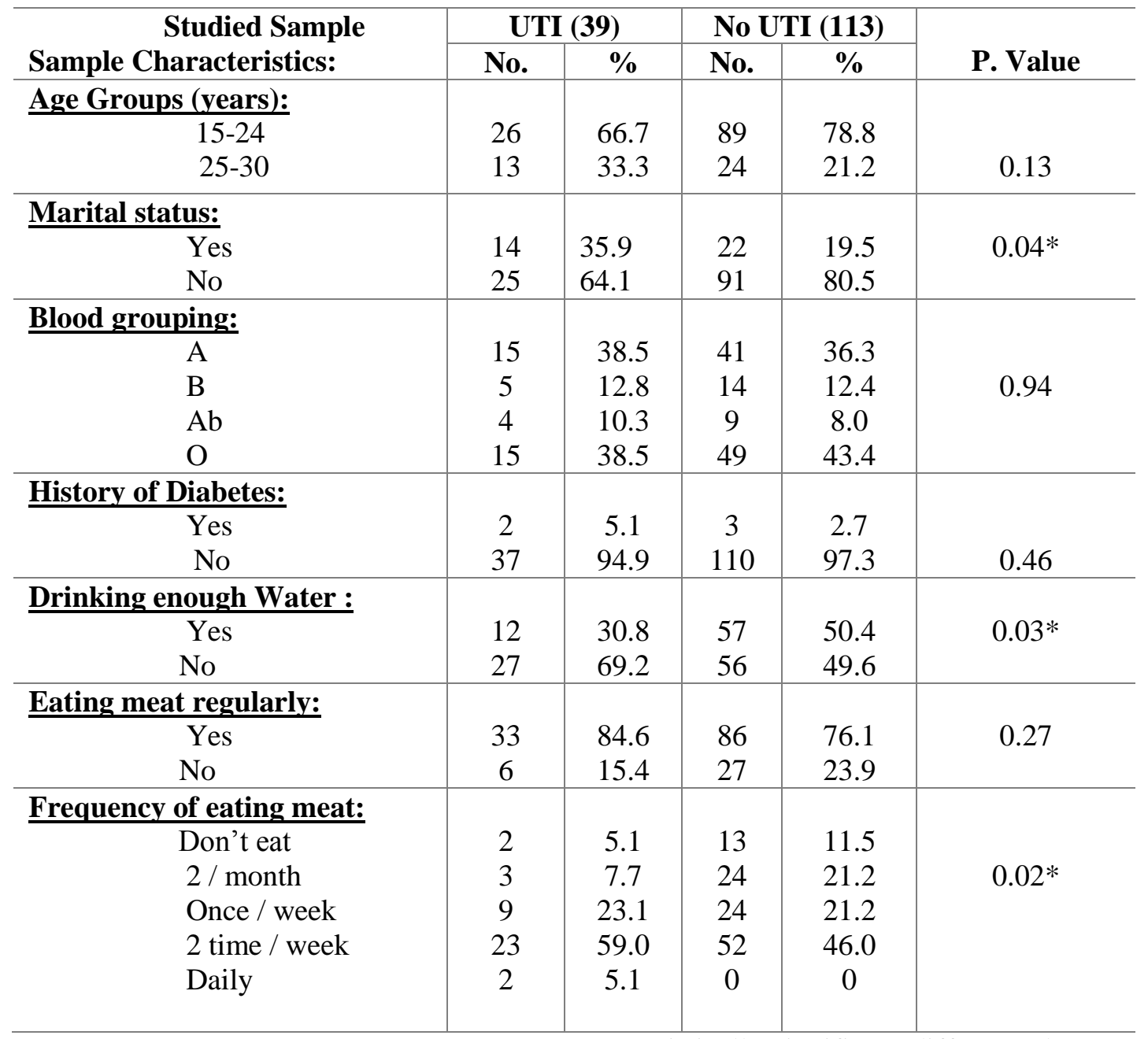

(*) mean the $\mathrm{P}$ value is $\leq 0.05$

Table (2) denotes the differentiation of the sample characteristic according to UTI affection (studied groups) among the studied sample. Regarding to age distribution, there was a significant higher percentage of UTI among the young age group 15-24 years than in older group. In a relation to the marital status, there was a significant higher percentage of UTI among the married women than in non-married. There was no statistically significant difference between the studied groups regarding to their blood groups and history of diabetes. Regarding to drinking enough water, there was a high significant percentage of UTI among the group who don't drink enough water than the group who drink enough.

About the habit of eating meat among the studied groups, there was no statistically significant difference between the studied groups regarding to their blood groups $(\mathrm{P} \geq 0.05)$. Concerning the frequency of eating meat there were significant differences according to the 
rate of eating; as low rate of eating meat (2 time/month) had a low percentage of UTI than the high rate of eating meat ( 2 time/ week) which had a high percentage of UTI.

\section{Multivariate analysis:}

Table (3): Logistic regression analysis of factors affecting urinary tract infection among female students.

\begin{tabular}{|c|c|c|c|c|}
\hline & \multirow{2}{*}{ Sig. } & \multirow{2}{*}{$\begin{array}{l}\text { Odds } \\
\text { Ratio }\end{array}$} & \multicolumn{2}{|c|}{ 95\% C.I. for OR } \\
\hline & & & Lower & Upper \\
\hline $\begin{array}{l}\text { Blood } \\
\text { grouping }\end{array}$ & 0.721 & & & \\
\hline A & 0.267 & 0.554 & 0.196 & 1.571 \\
\hline B & 0.741 & 0.765 & 0.155 & 3.764 \\
\hline $\mathrm{Ab}$ & 0.932 & 0.944 & 0.249 & 3.570 \\
\hline $\begin{array}{l}\text { Marital } \\
\text { status }\end{array}$ & 0.424 & & & \\
\hline Marriage & 1.000 & $\begin{array}{r}318543 \\
572.659\end{array}$ & 0.000 & \\
\hline $\begin{array}{l}\text { Not } \\
\text { Marriage }\end{array}$ & 0.190 & 0.487 & .166 & 1.429 \\
\hline Pregnancy & 0.873 & 0.792 & 0.045 & 13.787 \\
\hline Diabetes & 0.952 & 1.076 & 0.097 & 11.991 \\
\hline $\begin{array}{l}\text { Drink } \\
\text { sufficient } \\
\text { Water }\end{array}$ & 0.045 & 2.504 & 1.020 & 6.147 \\
\hline Eat Meat & 0.980 & 0.982 & 0.244 & 3.949 \\
\hline $\begin{array}{l}\text { Frequency } \\
\text { of eating } \\
\text { meat }\end{array}$ & 0.373 & & & \\
\hline $\begin{array}{l}2 \text { times } \\
\text { /month }\end{array}$ & 0.999 & $\begin{array}{r}11461062 \\
533.84\end{array}$ & 0.000 & \\
\hline $\begin{array}{c}\text { Once } \\
\text { weekly }\end{array}$ & 0.999 & $\begin{array}{r}04223965 \\
20.16\end{array}$ & 0.000 & \\
\hline $\begin{array}{c}2 \\
\text { times/ week }\end{array}$ & 0.999 & $\begin{array}{r}34351762 \\
33.4\end{array}$ & 0.000 & \\
\hline Daily & 0.999 & $\begin{array}{r}30425506 \\
96.5\end{array}$ & 0.000 & \\
\hline $\begin{array}{l}\text { Aske a } \\
\text { medicine }\end{array}$ & 0.641 & 1.585 & 0.229 & 10.958 \\
\hline $\begin{array}{l}\text { No. of } \\
\text { clinical } \\
\text { visit }\end{array}$ & 0.915 & 1.116 & 0.147 & 8.482 \\
\hline $\begin{array}{l}\text { Treatment } \\
\text { taking for } \\
\text { UTI_ }\end{array}$ & 0.500 & 0.326 & 0.013 & 8.481 \\
\hline $\begin{array}{l}\text { Duration of } \\
\text { UTI } \\
\text { treatment }\end{array}$ & 0.292 & 1.091 & 0.928 & 1.284 \\
\hline $\begin{array}{l}\text { No. of UTI } \\
\text { recurrent }\end{array}$ & 0.553 & 0.902 & 0.641 & 1.269 \\
\hline $\begin{array}{l}\text { UTI } \\
\text { symptoms }\end{array}$ & 0.132 & 1.244 & 0.937 & 1.652 \\
\hline
\end{tabular}

Table (3) shows the logistic regression analysis of factors affecting urinary tract infection among female students. According to the value of OR we noticed that, the ranking of the most affecting factors on UTI were frequency of eating meat, marital status and drinking enough water.

\section{DISCUSSION}

In this study, the data showed that most participants $(75.66 \%)$ are fitting criteria of being young females in the age group of 15-24. The condition of LUTI is well known to be among common complaints in females ${ }^{(20-22) .}$

In the present study, about $35.9 \%$ of participants were married, which was significantly $(\mathrm{P}=0.04 *)$ correlated with presence of LUTI. Recurrent cystitis associated with sexual intercourse is quite common in young women; however not all sexually active women will suffer a post-coital UTI episode. Behavioral risk patterns, genetic factors and increased virulence of certain subtypes of uropathogen were affect the severity of UTIs ${ }^{(23)}$. The shorter distance of the urethra to the anus has been the only anatomical risk factor described that is marginally significant in predisposing women for UTIs ${ }^{(24) \text {. }}$

Although presence of diabetes in the studied sample is insignificant, it can be one of predisposing factors for LUTI $^{(25)}$. The percentage of diabetic students seemed to lie within those suffered from LUTI and gave history of increased red meat intake.

Significant decrease in LUTI was found among students, who gave history of suitable amount of water intake. Drinking enough water was significantly associated with less prevalence of LUTI ${ }^{(2)}$.

The interesting finding is that the percentage of females having symptoms of LUTI (25.66\%) nearly matches the percentage of those who had an increased red meat consumption (21.71\%). An association between red meat intake and urine acidity was reported in literature (26). Increased urine acidity was usually associated with bladder mucosa irritation that unless treated may end in cystitis and severe complication ${ }^{(10-12)}$. Crippa et al. ${ }^{(9)}$ reported that five cohort studies done on considerable number of cases pointed to a link between increased red meat consumption and cancer bladder.

\section{CONCLUSION}

Lower urinary tract symptoms are quite common among studied samples, it seemed to be related to increased trend towards red meat eating besides other factors such as water drinking and marital status. More screening methodology should be done to evaluate the association between symptomatic parameters and 
possible presence of any associated infections. The study may help raising awareness among educated students to seek medical advice if having any similar conditions.

\section{REFERENCES}

1. Ahmad R, Imran A, Hussain M (2018): Nutritional Composition of Meat. In Meat Science and Nutrition, IntechOpen. http://dx.doi.org/10.5772/intechopen.77045.

2.Weickert M, Pfeiffer A (2018): Impact of dietary fiber consumption on insulin resistance and the prevention of type 2 diabetes. The Journal of nutrition, 148(1): 7-12.

3.Quintana P, Sookthai D, Wittenbecher C et al. (2018): Red meat consumption and risk of cardiovascular diseases - is increased iron load a possible link?. The American journal of clinical nutrition, 107(1): 113-119.

4.Isaza, A (2019): Effects of Western Style Foods on Risk of Noncommunicable Diseases. In The Role of Functional Food Security in Global Health ,pp. 185-192. Academic Press.

5.Van Hecke T, De Vrieze, J, Boon N, De Vos W H, Vossen E, De Smet $S$ (2019): Combined Consumption of Beef- Based Cooked Mince and Sucrose Stimulates Oxidative Stress, Cardiac Hypertrophy, and Colonic Outgrowth of Desulfovibrionaceae in Rats. Molecular nutrition \& food research, 63(2):1800962.

6.Reistad R, Rossland O J, Latva-Kala K J, Rasmussen T, Vikse R, Becher G, Alexander J (1997): Heterocyclic aromatic amines in human urine following a fried meat meal. Food and Chemical Toxicology, Andersen, B. M. (2019): Urinary Tract Infections: Prevention. In Prevention and Control of Infections in Hospitals (pp. 583-609). Springer, Cham.

7.Cross A J, Major J M, Sinha R (2011): Urinary biomarkers of meat consumption. Cancer Epidemiology and Prevention Biomarkers, 20(6): 1107-1111.

8.González-Domínguez R, Urpi-Sarda M, Jáuregui O, Needs P, Kroon P A, Andres-Lacueva C (2019): Quantitative Dietary Fingerprinting (QDF)-A novel tool for comprehensive dietary assessment based on urinary nutrimetabolomics. https://www.researchgate.net/.../331336138_Quantitative_Dieta ry_Fingerprinting_QDF-

9.Crippa A, Larsson S C, Discacciati A, Wolk A, Orsini N (2018): Red and processed meat consumption and risk of bladder cancer: a dose-response meta-analysis of epidemiological studies. European journal of nutrition, 57(2):689-701.

10.Kobayashi H, Yoshiyama M, Zakoji H, Takeda M, Araki I (2009): Sex differences in the expression profile of acid-sensing ion channels in the mouse urinary bladder: a possible involvement in irritative bladder symptoms. BJU Int. , 104:174651

11.Sönmez M G, Göğer Y E, Ecer G, Atıcı A, Özkent M, Öztürk A (2018): Effects of urine alkalinization with sodium bicarbonate orally on lower urinary tract symptoms in female patients: a pilot study. International urogynecology journal, 1:5.

12.Marcovich R (2018): Nutrition Therapy for Specific Lithogenic Risk Factors: High Urine Uric Acid/Acid Urine. In Nutrition Therapy for Urolithiasis ,pp. 125-134. Springer, Cham.
13. Uddin M, Azhar F, Pearce I (2018): Bladder pain syndrome. Obstetrics, Gynaecology \& Reproductive Medicine, 28 (11-12): 333-338.

14.Hooton T M, Gupta K (2018): Acute simple cystitis in women. https://www.uptodate.com/contents/acute-simple-cystitis-inwomen.

15.Birder LA (2019): Bladder/Pelvic Pain and Neurogenic Inflammation. In: Liao L., Madersbacher H. (eds) Neurourology. Springer, Dordrech: pp. 433-446.

16.Haylen BT, de Ridder D, Freeman RM et al .(2010): An International Urogynecological Association (IUGA)/International Continence Society (ICS) joint report on the terminology for female pelvic floor dysfunction. Neurourol Urodyn ,29(1):4-20.

17.Wu M P, Luo H L, Weng S F, Ho C H, Chancellor M B, Chuang Y C (2018): Risk of Urinary Tract Carcinoma among Subjects with Bladder Pain Syndrome/Interstitial Cystitis: A Nationwide Population-Based Study. https://doi.org/10.1155/2018/7495081

18.Coyne KS, Sexton CC, Irwin DE, Kopp ZS, Kelleher CJ, Milsom I (2008): The impact of overactive bladder, incontinence and other lower urinary tract symptoms on quality of life, work productivity, sexuality and emotional well-being in men and women: results from the EPIC study. BJU Int., 101(11):1388-1395.

19.Farrel $\boldsymbol{E}(\mathbf{2 0 0 8})$ : Prevalence of urinary tract infection in childhood: a meta-analysis. The Pediatric infectious disease journal, 27 (4): 302-308.

20.Nguyen $A$ and Weir $B(2002)$ : Urinary tract infection as a possible marker for teenage sex. South Med J., 95(8): 867-9

21.Kodner CM, Thomas G(2010): Recurrent urinary tract infections in women: diagnosis and management. Am Fam Physician, 82(6): 638-43.

22.Medina-Bombardó D, Jover-Palmer A (2011): Does clinical examination aid in the diagnosis of urinary tract infections in women? A systematic review and meta-analysis. BMC Fam Pract ., 12:111.

23.Karam M R A, Habibi M, Bouzari S (2019): Urinary tract infection: Pathogenicity, antibiotic resistance and development of effective vaccines against Uropathogenic Escherichia coli. Molecular immunology, 108: 56-67.

24.Gyftopoulos K, Matkaris M, Vourda A, Sakellaropoulos G (2018): Clinical implications of the anatomical position of the urethra meatus in women with recurrent post-coital cystitis: a case-control study. https://link.springer.com/article/10.1007/s00192-018-3710-7

25.Liang Y, Liu Y, Ren S, Liu X, Yang Y, Zhu H, Xu L (2018): Self-monitoring of blood glucose and effectiveness analysis in subjects with diabetes related urinary tract infections (UTI) after subcutaneous insulin infusion. Int J Clin Exp Med., 11(7): 72887295 .

26.Cross A J, Sinha $R$ (2004): Meat- related mutagens/carcinogens in the etiology of colorectal cancer. Environmental and molecular mutagenesis, 44(1): 44-55. 